Although mid-arm circumference has been mainly used for nutritional assessment among children, ${ }^{23}$ it has been used in adults to assess dietary treatment with favourable results. ${ }^{5} \mathrm{Mid}$-arm circumference is simple to measure, and we believe it is a useful measurement in identifying a group of patients with Crohn's disease who are at risk of malnutrition and would benefit from more detailed nutritional assessment.

1 Dawson A. Nutritional disturbances in Crohn's disease. Proc $R$ Soc Med $1971 ; 64: 166-7$.

${ }^{2}$ Shakir A. Arm circumference in the surveillance of protein-calorie malnutrition in Baghdad. Am $\mathcal{F}$ Clin Nutr 1975;28:661-5.

3 Trowbridge F. Clinical and biochemical characteristics associated with anthropometric nutritional categories. Am f Clin Nutr 1979;32:758-66.

4 Jelliffe DB. The assessment of the nutritional status of the community. Geneva: WHO, 1966. (WHO Monograph Series No 53.)

${ }^{5}$ Bray G, Greenway F, Molitch M, Dahms W, Atkinson R, Hamilton K. Use of anthropometric measures to assess weight loss. Am 7 Clin Nutr $1978 ; 31: 769-73$.

(Accepted 24 August 1982)

University Hospital of Wales, Heath Park, Cardiff CF4 4XW

A D HARRIES, MA, MRCP, medical registrar in gastroenterology L JONES, SRD, dietitian

R V HEATLEY, MD, MRCP, senior lecturer in gastroenterology

J RHODES, MD, FRCP, consultant physician

E FITZSIMONS, BSC, MRCP, lecturer in haematology

\section{Screening for alcohol abuse in pregnancy}

The fetal alcohol syndrome has been thought to be the main hazard of alcohol abuse in pregnancy. It occurs only in women who regularly consume more than $100 \mathrm{~g}$ alcohol daily, and such drinking is usually obvious. The possible consequences of more moderate alcohol consumption-such as second trimester abortion, low birth weight, and delayed achievement of developmental goals-have received less attention ${ }^{12}$ and detection of these more moderate rates of consumption (30-80 g alcohol daily) is more difficult. Laboratory tests for the detection of excessive drinking have been undertaken almost exclusively in alcoholics or in male heavy drinkers and there are no data to show whether these tests are of value in detecting potentially harmful levels of alcohol consumption in pregnancy. We assessed the value of $\gamma$-glutamyl transpeptidase and mean cell volume measurements in detecting potentially harmful rates of alcohol consumption during pregnancy.

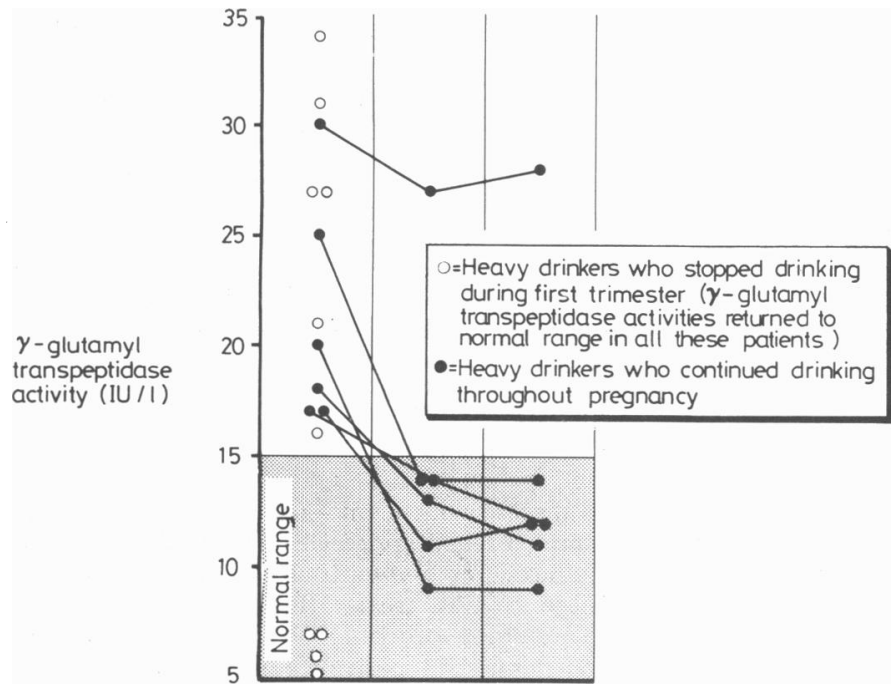

Serial $\gamma$-glutamyl transpeptidase activities in the six women who continued to drink heavily during pregnancy.

\section{Patients, methods, and results}

Alcohol consumption was assessed in 450 consecutive pregnant women attending the antenatal clinic at the West London Hospital. A questionnaire on prepregnancy drinking habits was filled in by the doctor at the booking clinic. The questionnaire has previously been validated at Charing Cross Hospital. ${ }^{3}$ The full blood count and mean cell volume were estimated using a Coulter counter " $S$ ". $\gamma$-Glutamyl transpeptidase activity was measured by the Szasz method ${ }^{4}$ on serum that had been separated within two hours of venepuncture and stored at $-4^{\circ} \mathrm{C}$. The questionnaire and measurement of $\mathcal{D}$ mean cell volume and $\gamma$-glutamyl transpeptidase activity were repeated in the second and third trimesters on random subsets of 100 women and on all women found to be drinking heavily in the first trimester. Women who had been taking more than $30 \mathrm{~g}$ of alcohol daily for more than 12 months were considered to be heavy drinkers.

Raised activities of $\gamma$-glutamyl transpeptidase were found in 12 out of 16 heavy drinkers in the first trimester; none were taking any drugs. Six of these 16 women continued to drink heavily at the same rate during pregnancy, but in only one was the $\gamma$-glutamyl transpeptidase activity persistently raised for the remainder of her pregnancy (figure). None of the 16 heavy drinkers had a raised mean cell volume (more than $100 \mathrm{fl}$ ) at any time during pregnancy, though six of the 16 had previously had a mean cell volume of more than $100 \mathrm{fl}$ documented. There were no significant differences between the normal ranges for $\gamma$-glutamyl transpeptidase activity in each trimester.

\section{Comment}

These findings show that mean cell volume is not a valuable measure of potentially harmful drinking during pregnancy and that $\gamma$-glutamyl transpeptidase is only of limited value in the first trimester. The observation that six out of 16 heavy drinkers had previously had a mean cell volume of greater than $100 \mathrm{fl}$ that returned to normal during $\omega$ pregnancy may be explained by the development of relative iron $\infty$ deficiency in the first trimester. Furthermore, the physiological rise in 은 mean cell volume $(4 \mathrm{fl})$ occurring during normal pregnancy means this $\sigma$ marker is probably only of value in detecting alcohol abuse during the $Z$ first trimester.

We found no significant difference between the mean activities of $\gamma$-glutamyl transpeptidase in each of the three trimesters, but others have reported a slight drop as pregnancy progresses. There is evidence that $\gamma$-glutamyl transpeptidase activities in pregnant women with viral hepatitis are lower in the second than in the first trimester and $\infty$ the rise in $\gamma$-glutamyl transpeptidase activities is attenuated in patients with acute hepatitis who are taking oral contraceptive preparations. ${ }^{5}$ Thus the failure to detect raised activities of $\gamma$-glutamyl transpeptidase in our patients who continued to drink in the latter stages of pregnancy may be due to hormonal factors. Both the mean cell volume and $\gamma$-glutamyl transpeptidase activity may be affected by drinking patterns but these did not change in the women in our study who were heavy drinkers.

We thank Sister Gillett and the staff of the antenatal clinic, West London Hospital, and Mr M Gordon, lecturer in computer science, Charing Cross Hospital Medical School, for help. This work is supported by the Health Education Council and the North-west Thames Regional Research Scheme. IGB was a Trustee's Research Fellow at Charing Cross Hospital.

1 Anonymous. Fetal alcohol advisory debated. Science 1981 ;214:642-4.

2 Barrison IG, Wright JT, Murray-Lyon IM. The hazards of moderate drinking in pregnancy. British fournal of Alcohol and Alcoholism 1981; 16:149-60.

${ }^{3}$ Barrison IG, Viola L, Mumford J, Gordon M, Murray RH, Murray-Lyon IM. Detection of excessive drinking amongst hospital admissions. Health Trends $1982 ; 14: 80-3$.

4 Szasz G. A kinetic photometric method for serum gamma-glutamyl transpeptidase. Clin Chem 1969;15:124-36.

5 Combes B, Shore GM, Cunningham FG, Walker FB, Shorey JW, Ware A. Serum $\gamma$-glutamyl transpeptidase activity in viral hepatitis: suppression in pregnancy and by birth control pills. Gastroenterology 1977;72:271-4.

(Accepted 24 August 1982)

Charing Cross Hospital and Medical School, London W6 8RF

I G BARRISON, MB, MRCP, clinical research fellow (now: senior registrar in medicine, West Middlesex Hospital, Isleworth, Middlesex)

I T WRIGHT, MRCOG, senior registrar in obstetrics and gynaecology (now at: West Middlesex Hospital, Isleworth, Middlesex)

B SAMPSON, BSC, MPHIL, biochemist, department of chemical pathology

N F MORRIS, MD, FRCOG, professor and consultant physician, obstetrics and gynaecology

IAIN M MURRAY-LYON, MD, FRCP, consultant physician, gastrointestinal unit 